\title{
El tratamiento de adjetivos en diccionarios para aprendices extranjeros de español
}

\author{
Helle Dam Jensen \\ School of Communication and Culture - Spanish Business Communication \\ Aarhus University \\ hed@cc.au.dk \\ Sven Tarp \\ Centre for Lexicography \\ Aarhus University \\ st@cc.au.dk
}

Resumen: Los aprendices extranjeros que redactan textos en español se enfrentan a menudo con dudas sobre las propiedades sintácticas de los adjetivos, entre ellas, su anteposición o posposición. Basado en un pequeño ejercicio y un análisis crítico de cuatro diccionarios para aprendices extranjeros del español, este artículo propone un modelo de cómo se pueden tratar las combinaciones sintácticas en futuros diccionarios digitales para este grupo de usuarios.

Palabras clave: diccionarios para aprendices extranjeros del español, redacción de textos en L2, adjetivos españoles, propiedades sintácticas, anteposición y posposición de adjetivos. 


\title{
Treatment of adjectives in Spanish dictionaries for foreign learners
}

\begin{abstract}
Foreign learners who write texts in Spanish are often in doubt about the syntactic properties of adjectives, e.g. their preposition or postposition. Based on a small test and an analysis of four Spanish learner's dictionaries, this contribution proposes a model of how syntactic combinations can be treated in future digital dictionaries for this particular user group.
\end{abstract}

Key words: Spanish learner's dictionaries, L2 text production, Spanish adjectives, syntactic properties, preposition and postposition of adjectives.

Recibido el 02/10/2018

Aceptado el 12/10/2018 


\section{Introducción}

Los aprendices extranjeros del español que redactan textos en esta lengua se enfrentan a menudo a grandes desafíos de tipo sintáctico. Entre los desafíos relacionados con el uso de los adjetivos, podemos mencionar su posición, régimen preposicional y otras posibles combinaciones sintácticas que, a veces, varían mucho de las que usan en su lengua materna.

En este artículo analizaremos cómo los diccionarios deben tratar las propiedades combinatorias para prestar más y mejor ayuda a los aprendices que busquen información específica sobre esta clase de palabra con el fin de escribir textos que trasmiten su mensaje de forma sintácticamente correcta. Nos centramos en un problema particular, la anteposición o posposición de los adjetivos, un fenómeno gramatical que supone un desafío para muchos estudiantes extranjeros, especialmente los que provienen de lenguas no románicas.

En el proceso de aprendizaje de una segunda lengua, el aprendiz suele encontrarse con diferentes clases de dificultades relacionadas con la lexicalidad, la gramática y la textualidad, entre otras. Este proceso puede complicarse aún más si la nueva lengua pertenece a una familia diferente a la de la lengua nativa. En lo que atañe a la gramática, el foco de este artículo, la investigación científica ha partido de diversos criterios en un intento de estructurar las dificultades que implica su adquisición para estudiantes extranjeros. DeKeyser (2005), por ejemplo, distingue entre problemas de significado, de forma y de mapeo entre forma $y$ significado.

Los autores de este artículo tenemos una experiencia acumulada de unos 50 años como profesores no nativos que enseñan el español como lengua extranjera a estudiantes daneses. Basándonos en nuestra experiencia, podemos afirmar que este grupo de estudiantes tienen sobre todo problemas con el aprendizaje de las construcciones gramaticales que no están gramaticalizadas en su lengua materna. En el caso concreto del español, esto se manifiesta de forma particular en lo relativo a los artículos, el modo y aspecto de los verbos y la posición de los adjetivos.

El español, como otras lenguas románicas, dispone de dos posiciones para el adjetivo atributivo, o sea, delante y detrás del sustantivo que modifica. Esta variación no existe en danés, pues lo que la lengua española expresa mediante la lexicalidad en combinación con la posición del adjetivo, se expresa únicamente por medio de la lexicalidad en danés. Pongamos como ejemplo el adjetivo único que se traduce al danés con dos adjetivos distintos (enestående y eneste) según su posición: 
Javier es un amigo único.

'Javier er en enestående ven.'

Javier es mi único amigo.

'Javier er min eneste ven.'

Único pertenece a un grupo de adjetivos cuyo significado se genera según su anteposición o posposición. En principio, muchos adjetivos pueden aparecer en ambas posiciones. En la práctica, sin embargo, la semántica inherente en algunos adjetivos puede restringir su uso en una u otra posición, de modo que estos adjetivos casi siempre aparecen en solo una de las dos posiciones. Este es el caso de los adjetivos relacionales, que siempre se posponen, tal como queda ilustrado en el siguiente ejemplo:

Esta tienda vende muchos productos orgánicos.

En resumen, hay diferentes factores que confluyen en la posición de los adjetivos, factores que han sido objeto de una multitud de estudios gramaticales que intentan identificar y explicitar el significado de cada posición y su relación con la semántica de los adjetivos. Numerosos trabajos científicos han intentado arrojar algo de luz sobre la complejidad relacionada con esta sección de la gramática española; ver Delbecque (1990), Demonte (1999), Dam (2008) Real Academia Española (2009) y Dam \& Dam Jensen (2018).

En los manuales de gramática, «delimitación» es una palabra clave con respecto a la posposición. Según la Real Academia Española (1973: 410) y Gómez Torrego (2011: 60), el adjetivo pospuesto delimita o restringe la extensión del núcleo. Jensen (2008: 83) y Mogensen (2001: 87) sostienen que esto da lugar a que una propiedad queda resaltada en detrimento de otras. La anteposición, a su vez, da lugar a explicación (RAE 1973: 410; Gómez Torrego 2011: 60) y, según algunos autores, también a valoración (RAE 1973: 410; Mogensen 2001: 88). Jensen (2008: 83) caracteriza la anteposición negativamente en relación a la posposición: no crea una comparación con otras propiedades ya que solo crea una relación con el sustantivo núcleo.

Las exposiciones de la gramática en libros y artículos científicos sirven para dotar a los estudiantes de profundos conocimientos sobre la gramática y las herramientas para trabajar metódicamente con ella. Sin embargo, estos conocimien- 
tos lingüísticos deben interiorizarse y convertirse en destrezas lingüísticas que son las que permiten a los aprendices manejar la nueva lengua con todas sus sutilezas y particularidades. Este proceso de interiorización se realiza por medio de la comunicación. El aprendiz que se dedica a la comunicación oral o escrita en una lengua extranjera, p.ej. la redacción de un texto, necesita muy a menudo una respuesta rápida a una duda gramatical que surge en tal contexto. Para satisfacer este tipo de necesidad, un diccionario de fácil acceso que recoja datos gramaticales y ofrezca indicaciones de uso sería, sin duda alguna, una herramienta idónea y hasta imprescindible.

En el siguiente apartado (2), presentaremos un ejercicio que realizamos para documentar el problema de la posición de los adjetivos. A continuación, discutiremos la interrelación entre diccionarios y manuales de gramática (apartado 3) y analizaremos el tratamiento de los adjetivos en los diccionarios existentes (apartado 4). Como resultado de esta discusión y análisis, presentaremos una propuesta de cómo se pueden tratar las propiedades en futuros diccionarios digitales para aprendices extranjeros del español (apartado 5). El artículo finaliza con las conclusiones.

\section{Ejercicio y resultados}

Como base del presente estudio, llevamos a cabo un ejercicio entre 21 estudiantes del segundo semestre de la licenciatura de Español de la Universidad de Aarhus, Dinamarca, o sea, un grupo de aprendices que pueden considerarse de nivel intermedio ya que han estudiado el español por lo menos dos años y medio si se incluye la enseñanza preuniversitaria. El objetivo era, por un lado, documentar que este grupo efectivamente tiene dificultades con el manejo de las posiciones de los adjetivos y, por otro lado, obtener más detalles sobre este problema. Por el reducido número de informantes, el ejercicio es únicamente informativo y sus resultados cuantitativos no pueden generalizarse.

La posición de los adjetivos es una cuestión que forma parte del curso de gramática del currículo del primer semestre, por lo que se podía suponer que los estudiantes ya tenían conocimientos básicos y sistemáticos del tema. Antes de empezar la actividad, la profesora repitió a modo de resumen el significado fundamental de las dos posiciones. La tarea incluía una colección de 31 oraciones en danés que los informantes tenían que traducir al español. En la traducción de cada oración, tenían que elegir una u otra posición del adjetivo indicado, tal como queda ejemplificado en el siguiente ejemplo: 
Jeg har købt de samme billetter. (mismo)

'He comprado los mismos billetes.'

La mayoría de los adjetivos seleccionados para el ejercicio pueden, en menor o mayor grado, cambiar de significado según su posición. Nuestra experiencia docente indica que los adjetivos con estas características son problemáticos para los estudiantes daneses. Cabe subrayar que hay un grupo bastante extendido de adjetivos que casi siempre se posponen porque su significado encaja con el significado de esta posición, por ejemplo, los de nacionalidad y de forma. A causa de esta sistematicidad se puede suponer que su uso está bastante automatizado, por lo que la tarea no incluía este tipo de adjetivos. Los doce adjetivos seleccionados son los siguientes:

$\begin{array}{llll}1 \text { último } & 4 \text { cierto } & 7 \text { propio } & 10 \text { único } \\ 2 \text { presunto } & 5 \text { medio } & 8 \text { mismo } & 11 \text { posible } \\ 3 \text { antiguo } & 6 \text { puro } & 9 \text { varios } & 12 \text { diferente }\end{array}$

A continuación, comentaremos las tendencias más importantes del ejercicio. Primero cabe subrayar que, en la evaluación de los resultados, se podía ver que algunos estudiantes, en vez de seleccionar la anteposición o posposición del adjetivo, o eligieron un adjetivo distinto al indicado o no tradujeron la oración. Cada una de estas soluciones se cuenta como inseguridad sobre la posición.

El ejercicio incluía un adjetivo con anteposición obligatoria, presunto, y otro, último, que en el caso concreto debe estar antepuesto aunque, en algunos casos, también puede estar pospuesto. Como no hay una relación clara entre su lexicalidad y la anteposición, los estudiantes tienen que recordarlos como casos singulares, y nos parecía interesante averiguar sus conocimientos sobre la posición de estos dos adjetivos. Los resultados revelan que todos los estudiantes, menos dos, habían puesto presunto en la posición correcta, mientras que sólo uno se había equivocado en cuanto a la posición de último.

Partiendo de los resultados del ejercicio, se puede extraer un grupo de tres adjetivos entre los doce estudiados que exponen una regularidad en la combinación posición-lexicalidad. Estos adjetivos son antiguo, cierto y puro. La mayoría de los estudiantes sabían cuál de las posiciones genera un significado y cuál genera otro. Suponemos que esto tiene que ver con que el significado generado en cada una de las posiciones se deja explicitar, delimitar y parafrasear con facilidad, por ejemplo, en el caso de antiguo: viejo<>anterior, lo que hace que los estudiantes 
recuerden mejor la posición que deben elegir para obtener el significado deseado. Cabe mencionar, sin embargo, que, en el caso de cierto, en el sintagma «cierta cantidad de agua», casi todos incluían el artículo («una cierta cantidad»).

Los seis restantes adjetivos presentaban más problemas para los estudiantes. En el caso de varios, era obvio que los estudiantes están familiarizados con el significado que genera la anteposición, pero que la mayoría de ellos no conocían el significado generado por la posposición («...tienen usos varios»).

Propio y medio implican una dimensión adicional en tanto que el uso de los adjetivos afecta al uso del artículo. En el caso de propio, los estudiantes se confundieron en ambas posiciones. El ejercicio incluía una construcción que requería el artículo determinado y otra con el artículo cero: «...es una utopía acceder a la vivienda propia»; «No tienen coche propio». En el primer caso, siete estudiantes habían elegido la solución correcta, mientras que, en el último caso, solo cinco estudiantes eligieron la construcción correcta. Otra complicación con respecto a este adjetivo se nota en la construcción predicativa. Ningún estudiante dominaba la construcción: «...es propio de cada persona».

En el caso de medio, la prueba incluía cuatro oraciones. Tres de ellas requerían la anteposición y el artículo cero, pero varían entre sí en la función gramatical del sintagma (sujeto/objeto directo) y en el tipo de núcleo, lo que podía influir en la solución. La mayoría de los estudiantes eligieron la anteposición para obtener el significado correcto, pero incluían, erróneamente, el artículo definido en las dos primeras oraciones, p.ej.: «la media ciudad». La cuarta oración con medio requería la posposición, y casi la totalidad de los estudiantes optaron por esta posición para obtener el significado «promedio». En resumen, el mayor problema con medio no residía en el uso del adjetivo, sino en el uso del artículo.

La tarea incluía tres oraciones con mismo: dos con anteposición («...los mismos billetes» $y$ «son los mismos estudiantes los que...») y una que permite tanto la anteposición como la posposición. En la primera de las oraciones con anteposición, el significado deseado es el de identidad entre dos entidades. Casi todos los estudiantes habían elegido la anteposición para obtener este significado. En la otra, el significado tenía que ser el de reforzar la identidad de las personas. Búsquedas en Google muestran que, para obtener este significado en esta oración en concreto (otros contextos pueden requerir la posposición para obtener el mismo significado), el adjetivo debe ir adelante del nombre. Solo seis de los estudiantes habían optado por la anteposición. En la tercera oración, el significado deseado era el de reforzar la identidad de un evento. Para conseguir este significado, ambas posiciones eran posibles, aunque la posposición sería la más adecuada en la oración en cuestión («Compraron las entradas en el espectáculo mismo») para 
evitar el significado de identidad entre dos entidades. Sin embargo, la mayoría de los estudiantes habían elegido la anteposición.

Había tres oraciones con único: una oración con anteposición, una con posposición y una con nominalización del adjetivo en el atributo («Eres la única...»). Casi la totalidad de los estudiantes sabían que la nominalización del adjetivo se realiza por medio del artículo definido. Sin embargo, tanto en la posposición como en la anteposición había inseguridad sobre la posición viz-á-viz significado.

En el caso de posible, más o menos la mitad de los estudiantes se equivocaron en la anteposición, mientras que más de la mitad acertaron en la posposición.

Había dos oraciones con diferente, una con posposición y una en la que la anteposición era preferible. En la oración con posposición, cuatro estudiantes se equivocaron. En la oración con anteposición, sin embargo, los resultados no son unívocos ya que la oración también admite la posposición con un significado ligeramente distinto: «...pueden elegir entre (diferentes) platos (diferentes)». Los resultados se distribuyen por igual entre las dos soluciones. Aunque la posposición no sea un error, se puede decir que la diferenciación de significado que existe en español, aunque sea una sutileza, es una sistematicidad en la lengua que deben conocer los estudiantes de español. Aun así, los resultados indican que no se puede dar por sentado que ellos sepan aplicar esta sistematicidad o regla general a un caso concreto.

En resumen, hay errores en la posición del adjetivo en todas las oraciones, menos en el caso de último. Los adjetivos varían entre sí en lo que se refiere a los desafíos que implican. En los casos en que el significado se deja explicitar en términos bastante claros y sin una sintaxis que influye en el uso (p.ej. artículos), hay bastante seguridad entre los estudiantes con respecto a la selección de posición. Sin embargo, en los demás casos observamos dificultades de diversa índole en la selección de la posición. Estos resultados, obviamente, no permiten generalizaciones, pero indican que hay estudiantes para los que el uso de los adjetivos resulta complicado, lo que concuerda con las observaciones que hemos hecho en el aula.

En los apartados 4 y 5 , profundizaremos en el tratamiento lexicográfico de cuatro de los adjetivos (diferente, mismo, posible y único) que más problemas han creado para los estudiantes, pero antes discutiremos brevemente el papel que pueden jugar los diccionarios con respecto a las necesidades gramaticales de sus usuarios. 


\section{Dicotomía entre diccionarios y manuales de gramática}

Entre los estudiosos de la lexicografía hay una larga tradición de discutir la relación entre diccionarios y manuales de gramática, una discusión que tiene especial relevancia para los aprendices de una segunda lengua que necesitan ayuda para escribir textos en esta lengua. Después de analizar las gramáticas y diccionarios de su época, Sweet (1899: 125) resumió que aquellas recogían los «fenómenos de la lengua» que podían expresarse en «reglas generales» en tanto que estos se limitaban a tratar los «fenómenos aislados», en particular el significado de las palabras por separado. Sin embargo, el que se considera el «padre» de la lexicografía pedagógica inglesa no se conformó con esta situación y recomendó que «un diccionario totalmente útil» debiera informar sobre diferentes «detalles gramaticales» que son demasiado numerosos, arbitrarios o complicados para ser tratados en una gramática normal. Propuso, por consiguiente, que se compilara un diccionario que sirviera de «referencia gramatical» y recogiera «las construcciones gramaticales que caracterizan palabras individuales y no se deducen fácilmente y con certeza de las reglas gramaticales generales»:

A thoroughly useful dictionary ought, besides, to give information on various grammatical details, which, though they fall under general rules of grammar, are too numerous or too arbitrary and complicated to be treated of in detail in any but a full reference-grammar: such a dictionary ought to give full information about those grammatical constructions which characterize individual words, and cannot be deduced with certainty and ease from a simple grammatical rule (Sweet 1899: 139).

Las ideas de Sweet iban aplicándose poco a poco en los diccionarios diseñados para aprendices extranjeros del inglés. Casi un siglo después, el entonces editor del prestigioso Oxford Advanced Learner's Dictionary, Anthony Cowie, pudo constatar que el tratamiento de las particularidades sintácticas y el uso de códigos sofisticados para este fin venían extendiéndose durante los años anteriores:

Few developments in monolingual EFL lexicography in recent years have aroused as much critical and speculative comment as the grammatical treatment of entrywords. The period since 1974 has seen an extension of the dictionary coverage of particular syntactic features, and a growth in the use and sophistication of coding systems. Feedback from the classroom is now accumulating in the form of a vigorous and well-documented literature with a number of characteristic perspectives, some mainly linguistic, others more directly concerned with practical issues of interpretability and usefulness. (Cowie 1987: 183). 
Con respecto a la «interpretabilidad y utilidad» a que se refería Cowie, un estudio conducido por el investigador japonés Yukio Tono (1986) ya había demostrado que los usuarios rara vez se beneficiaban de los códigos gramaticales suministrados en los diccionarios que consultaban. Y tres años después, el mismo Cowie expresó una opinión similar al constatar que «la información codificada plantea problemas de interpretación y uso para los aprendices extranjeros» (Cowie 1989: 589).

El problema radicaba principalmente en el hecho de que los códigos gramaticales solían presentarse en un lenguaje muy abstracto con el uso de abreviaturas y una terminología lingüística que la mayoría de los usuarios desconocían. Muchos editores de diccionarios se dieron cuenta de que había que cambiar de estrategia y adaptarse aún más a las necesidades reales de sus usuarios, incluso si esto implicaba transigir con la descripción lingüística. En esos momentos, había una fuerte competencia entre cinco grandes proyectos de diccionarios ingleses para aprendices extranjeros, los llamados Big Five, y la innovación se planteaba como algo urgente y necesario para el éxito comercial.

Quizás por eso, solo una década más tarde Michael Rundell, el editor de los diccionarios Macmillan, pudo identificar «dos claras tendencias» en los más recientes diccionarios para aprendices extranjeros, o sea, por un lado la introducción de una «codificación más transparente» y, por otro, un «esfuerzo más sistemático para asegurar que la información suministrada en códigos se reflejara en ejemplos y (cada vez más) también en definiciones»:

Two clear trends can be identified here: first, a move towards more transparent coding, and secondly a more systematic effort to ensure that information supplied in codes is mirrored in examples and (increasingly) in definitions too (Rundell 1998: 329).

Rundell se percataba de que la mayoría de los sistemas de codificación ahora exigían pocos conocimientos gramaticales a sus usuarios y aspiraban a resolver los problemas de estos sin que necesitaran consultar tablas y gráficas explicativas para descifrar los códigos. A este respecto observa que «se ha sacrificado cierta delicadeza de descripción por la necesidad de obtener la máxima claridad» ( $\mathrm{p}$. 330), por lo que algunos patrones que son gramaticalmente diferentes y, por eso, habían tenido diferentes códigos en los diccionarios anteriores, «ahora se tratan puramente desde el punto de vista de sus características superficiales» (p. 330) y, en consecuencia, reciben el mismo código.

Ni Cowie ni Rundell se expresan directamente sobre la visión de Sweet según la que el diccionario, para ser «totalmente útil», debe convertirse en una «referencia gramatical» que informe sobre los detalles gramaticales que caracterizan 
las palabras individuales y no se deducen fácilmente de las reglas generales. Pero su trabajo apunta claramente en la misma dirección.

Ahora bien, ¿en qué medida debe el diccionario informar sobre estos detalles? Con matices, los lexicógrafos de habla inglesa tienen varias respuestas a esta pregunta. El lexicógrafo egipcio Al-Kasimi (1977: 50), por ejemplo, opina que un diccionario debe «ofrecer toda la información que necesite el aprendiz extranjero sin que este sea remitido a los manuales de gramática».

En cambio, el investigador alemán Thomas Herbst (1989: 94), para quien los manuales de gramática recogen las «características generalizables de la lengua» y los diccionarios »sus idiosincrasias», parece defender la posición de que solo la «información gramatical que no puede generalizarse» tiene su sitio en el diccionario. En este sentido, Herbst está en línea con su colega británico Howard Jackson, quien opina que todos los datos sintácticos que no se deducen de las reglas generales de la gramática deben tratarse en los artículos individuales del diccionario:

All these facts about the syntactic operation of certain members of certain word classes are particular facts about individual lexical items, and are not deducible from the general rules of grammar [...]. They are appropriately stated in the dictionary entries for the lexical items. (Jackson 1985: 57)

La discusión sobre los datos gramaticales que deben o no deben incluirse en los diccionarios ingleses para aprendices extranjeros es especialmente rica debido a la importancia del inglés como lengua franca a nivel internacional y debe, por lo tanto, ser una fuente de inspiración (pero no de copia) para los lexicógrafos que se enfrentan a problemas similares en otras lenguas.

Si miramos la situación dentro de la lexicografía pedagógica con el español podemos constatar que ha habido, y hay, una discusión académica más o menos parecida, pero lejos de ser tan rica como la inglesa y, como veremos, hasta cierto punto limitada por el actual estado de los diccionarios pedagógicos. Entre los textos que tratan sobre este tema, podemos mencionar Cos (2004), Garrudo (2004), Santamaría (2004) y Tarp (2018). La penúltima, por ejemplo, suscribe la necesidad de incorporar datos gramaticales en los diccionarios aunque se limita a discutir el problema a partir del verbo:

Tras la muestra analizada podemos concluir que en los diccionarios dedicados a hablantes no nativos no es suficiente con indicar las distintas acepciones de significado; estas tienen que ir acompañadas de las indicaciones necesarias acerca de las particularidades construccionales de cada una de ellas, pero además diferenciando los diferentes argumentos sintáctico-semánticos exigidos por el verbo en cada una de esas construcciones (Santamaría 2004: 577). 
A pesar de apoyar la incorporación de datos gramaticales en los diccionarios pedagógicos, Santamaría también expresa cierta reserva respecto a este problema, pues rechaza explícitamente la idea de convertir el diccionario en una «referencia gramatical»:

Queremos dejar claro que una obra lexicográfica no puede incorporar todos los usos gramaticales de cada una de las entradas, ya que entonces el diccionario se convertiría en una obra que recoge la gramática particular de cada palabra, lo cual no es el objetivo del diccionario. No cabe duda de que este tipo de información debe incorporarse, pero es difícil establecer los límites acerca de cuánta gramática debe aparecer en los diccionarios (Santamaría 2004: 577).

Lamentablemente, Santamaría no explica por qué el «objetivo del diccionario» no puede ser el de recoger «la gramática particular de cada palabra», pues un diccionario con estas características sería indudablemente de gran utilidad para el aprendiz extranjero, especialmente cuando tiene problemas relacionados con la producción de textos. Si nos centramos únicamente en los diccionarios impresos, es obvio que la inclusión de todos los datos necesarios sería difícil, si no imposible, y en este sentido se justifica el planteamiento de Santamaría. Pero hoy en día vivimos en el mundo digital donde ya no hay límites técnicos que obstaculicen el almacenamiento y presentación didáctica de estos datos. El único límite es de tipo financiero. Por eso, pensamos que la visión de Sweet debe convertirse en una aspiración constante de todos los lexicógrafos que compilan diccionarios para hablantes no nativos.

\section{El tratamiento en los diccionarios existentes}

A continuación, vamos a ver cómo los diccionarios para aprendices del español como lengua extranjera manejan el problema de las propiedades sintácticas del adjetivo. Actualmente, hay varios diccionarios que -en su título, dorso o prólogo- declaran que se han elaborado para ayudar a estudiantes extranjeros. Sin embargo, la mayoría de ellos también incluyen hablantes nativos en su grupo destinatario, un desenfoque conceptual que resulta problemático ya que los dos tipos de usuarios no tienen el mismo punto de partida y, por lo tanto, las mismas necesidades lexicográficas.

En España solo se han publicado tres diccionarios que se han compilado exclusivamente para aprendices de español: DAELE, que, transcurridos diez años, solo ha terminado 353 verbos; BIENVENIDOs, que se centra en el aprendizaje del vocabulario por medio de tablas ilustrativas y sin tratar la sintaxis; y SM, que es el único de estos diccionarios que contiene los datos gramaticales que nos interesan. Como consecuencia, y para tener suficientes datos empíricos, estudiaremos tam- 
bién tres diccionarios que se dirigen a usuarios tanto nativos como no nativos. En total, hemos seleccionado los siguientes cuatro diccionarios para nuestro análisis:

- Diccionario de la lengua española para estudiantes de español (ESPASA)

- Diccionario Salamanca de la lengua española (salamanca)

- Diccionario de español para extranjeros (SM)

- Diccionario para la enseñanza de la lengua española. Español para extranjeros (vox)

Todos estos diccionarios se han concebido desde cero para el medio impreso. Solo dos de ellos, salamanca y vox, se han colocado posteriormente en Internet en versión digitalizada, lo que les califica como «caballos más rápidos» según la clasificación de Tarp (2011). Esto significa, entre otras cosas, que no hacen pleno uso de las nuevas tecnologías para crear un producto personalizado que se adapte a las necesidades específicas de sus usuarios en cada consulta; ver FuertesOlivera \& Tarp (2014).

A modo de ejemplo, solo analizaremos artículos con cuatro de los adjetivos que más problemas crearon para los estudiantes daneses que participaron en el ejercicio (ver apartado 2), a saber: diferente, mismo, posible y único. Además, y para no extendernos excesivamente, nos centramos únicamente en los aspectos lexicográficos relacionados con la construcción sintáctica.

\subsection{Diferente}

A continuación, reproducimos los cuatro artículos completos con diferente:

ESPASA:

di+fe+ren+te adj. 1 Diverso, distinto, que no es igual: Desde que perdió su trabajo es una persona . $2 \mathrm{adv} . \mathrm{m}$. De forma distinta: Ahora opino .

\section{SALAMANCA:}

diferente adj. 1 (ser/estar; antepuesto/pospuesto) Que no tiene la misma naturaleza, cantidad o calidad que otra persona, animal o cosa: Es una sensación diferente, nunca habia experimentado nada igual. Son cuatro hermanos completamente diferentes. Aunque se parezcan mucho, su vestido es diferente del mío. Se puede abordar el tema desde diferentes puntos de vista. No sé, está diferente, 
'has hecho algún cambio? sin. distinto. ANT, igual. || adv. 2 De manera distinta: Su estilo ya no es el mismo, ahora pinta diferente, con más realismo. ANT. igual.

$\mathrm{SM}+$

di.fe+ren+te adj. inv. (ser/estar) Distinto o que no es igual: Los dos sois muy diferentes porque tú eres tranquila y él, nervioso. Con este flequillo estás diferente. $\square$ AnT. idéntico.

vox:

$\mathrm{di}+\mathrm{fe}+\mathrm{ren}+\mathrm{te} 1 \mathrm{adj}$. Que es distinto a otro; que no es igual: La idea que yo tengo es $\sim$ a la tuya, todas las personas son diferentes, $=>$ diverso. $\leftrightarrow$ coincidente. 2 diferentes adj. pl. Varios; más de uno, cuando no son iguales: la cuestión presenta diferentes aspectos; hay diferentes modos de ver la misma cosa. $\leftrightarrow$ distinto.

Inicialmente observamos cómo los artículos reproducidos aquí exhiben algunos de los vicios clásicos que en gran medida caracterizan la lexicografía impresa con español: (a) el tratamiento de diferentes clases de palabras bajo la misma entrada, lo que complica el acceso; (b) el uso de abreviaturas y símbolos, lo que estorba la comprensión; y (c) el empleo excesivo de itálica, lo que reduce la legibilidad y anula el efecto enfático de esta técnica. Aunque no es nuestro tema directo, estos vicios afectan también a la accesibilidad y utilidad de los datos que nos interesan.

Aparte de esto, vemos cómo todos los artículos ofrecen ejemplos que implícitamente informan sobre las propiedades sintácticas de diferente, y que dos de ellos, SM y SALAMANCA, también contienen datos explícitos sobre estas propiedades (ser/estar; antepuesto/pospuesto). Esta última combinación de datos explícitos e implícitos representa un método muy didáctico pues se sabe que algunos usuarios pueden conformarse con los datos explícitos mientras que otros necesitan los implícitos para entender aquellos; ver Tarp (2008: 234). Al contrario, es dudoso que todos los usuarios puedan deducir las minireglas sintácticas si el diccionario solo suministra ejemplos implícitos como es el caso de ESPASA y vox, pues la deducción de reglas generales a partir de los datos implícitos, y sin la mediación de los explícitos, es una operación mental compleja que no necesariamente tiene el resultado deseado.

Otro problema que observamos en los cuatro diccionarios es la misma posición de los ejemplos que, en todos los artículos reproducidos, se facilitan inmediatamente detrás de la definición y los dos puntos. Esta forma de presentarlos, 
probablemente inspirada en las ideas de Seco (1987), hace pensar que su función principal es la de ser suplemento de la definición. Es innegable que esta función puede ser útil para muchos usuarios, pero no debemos olvidar que los ejemplos lexicográficos tienen varias finalidades, entre ellas la de ilustrar los datos sintácticos explícitos, y que cada una de estas finalidades requieren diferentes criterios de selección para conseguir ejemplos con las características deseadas. Es difícil encontrar ejemplos que sirvan para todos los fines. Por ello, deben seleccionarse y colocarse en función de cada dato explícito, sea este una definición, un dato sintáctico, etc.

A este respecto, también es problemático que los distintos datos explícitos (códigos) se agrupen juntos al inicio del artículo en vez de presentarse por separado seguido de sus propios ejemplos ilustrativos. Si se presentaran de esta última forma, sería mucho más fácil para el usuario establecer la relación entre uno y otro, algo que también reduciría el tiempo total empleado en la consulta. Como bien dice Rundell (1998), no debemos presuponer un papel más activo de los usuarios ya que estos quieren resolver sus necesidades de información lo más rápido posible:

We would be unwise to produce dictionaries that relied on more active engagements by users. On the whole, learners want to find information quickly and be able to grasp it immediately once they find it. (Rundell 1998: 330)

Incluso con los datos explícitos e implícitos ubicados juntos, podría ser difícil para el usuario determinar cuándo debe emplear una u otra forma de construcción. Para remediar esta incertidumbre, haría falta una nota con claras indicaciones de qué hacer. Por ejemplo, sorprende que vox sea el único de los cuatro diccionarios que ofrece dos acepciones de diferente, lo que le permite indicar con qué sentido este adjetivo (en plural) se antepone a un sustantivo. Otro ejemplo es la construcción con ser o estar. El uso de estos dos verbos en combinación con adjetivos se rige por reglas generales que se recogen en los manuales de gramática. Sin embargo, la experiencia muestra que los aprendices extranjeros, especialmente los principiantes, tienen grandes dificultades en el momento de aplicar estas reglas en oraciones concretas.

Entonces, ¿qué debemos hacer? Estamos claramente ante «los límites de cuánta gramática debe aparecer en los diccionarios» (Santamaría 2004). ¿Debemos seguir la orientación de Jackson (1985) y Herbst (1989) de solo tratar los fenómenos individuales que no pueden deducirse de las reglas gramaticales generales? ¿O debemos adherirnos a la visión de Sweet (1899) de explicar todos los «detalles gramaticales» que no se deducen «fácilmente y con certeza» de las reglas generales? 
Puede que la diferencia entre las dos posiciones parezca ínfima, pero ya se sabe que el diablo se esconde en los detalles. Por eso, y si el objetivo del diccionario es prestar la máxima ayuda posible a sus usuarios, parece más sensato seguir los pasos de Sweet y ofrecer un pequeño paquete gramatical compuesto por una miniregla, un ejemplo y una nota explicativa e indicativa. En nuestras propuestas (apartado 5), mostraremos cómo se puede configurar tal paquete gramatical.

El último comentario sobre diferente trata del régimen preposicional. Vemos cómo solo dos de los diccionarios aportan ejemplos con el uso de preposiciones en combinación con este adjetivo: La idea que yo tengo es a la tuya (vox); Aunque se parezcan mucho, su vestido es diferente del mio (salamanca), donde el uso de la negrita en este último tiene una función semi-explícita.

Estas construcciones preposicionales, de uso más o menos semejante, son bastante frecuentes en español según búsquedas en Google y, por lo tanto, relevantes para los aprendices extranjeros de esta lengua. No obstante, para que sean totalmente útiles para este grupo destinatario, pensamos que deben incluirse datos adicionales que informan explícitamente sobre sus posibles complementos, o sea, si estos son animados o inanimados. Además, para evitar que los usuarios pierdan tiempo reflexionando sobre la posible diferencia entre las dos preposiciones, recomendamos que se añada una pequeña nota explicando que son sinónimos y pueden usarse indistintamente (ver apartado 5). Alternativamente, y como el objetivo último del diccionario no es describir la lengua española, sino ayudar a los aprendices extranjeros a escribir en esta lengua con la introducción de datos explícitos acerca de su funcionamiento, se puede considerar que solo se presenta una variante, con la que el aprendiz puede resolver su problema sin tener que elegir entre una u otra opción.

\subsection{Mismo}

Ahora procedemos a analizar el adjetivo mismo. Para este y los siguientes adjetivos solo discutiremos la problemática que aún no hemos tocado, y por esta misma razón eliminaremos de los artículos todos los datos lexicográficos que no tienen relevancia para nuestro tema, entre ellos los sinónimos, antónimos, locuciones y adverbios.

\section{ESPASA:}

mis·mo, ma adj. 1 Indica que se trata de una persona o cosa a la que se refiere, y no a otra: Es el $\sim$ coche que vimos ayer. 2 Semejante o igual: Usamos la misma talla. 3 Con sustantivo y pronombres, refuerza la identidad: Yo $\sim$ lo haré. 4 Precedido de adverbio, refuerza su significado, añadiendo precisión: Fue ayer . [...] 
SALAMANCA:

mis.mo, ma 1 adj./pron. 1 (antepuesto) [Persona, animal, cosa] que es una sola en distintas ocasiones o en distintos lugares: Me encontré en Valladolid con los mismos excursionistas que en Soria. 2 Que es igual o semejante: Tenéis la misma estatura. Madre e hija tienen los mismos ojos. || adj. 3 (antepuesto/pospuesto a un sustantivo; pospuesta a un pronombre) inTENSIFICADOR. Subraya la identidad del sustantivo o pronombre a los que se refiere: El mismo príncipe lo dijo. El príncipe mismo lo dijo. I| pron. 4 (precedido de artículo) Señala que la persona, animal o cosa a que se refiere no ha cambiado: Es el mismo de siempre. - «Tiene todavía novia?»-«Hace años que sale con la misma». [...]

SM:

mis·mo, ma adj. 1 Que es idéntico y no otro diferente: En las ceremonias y actos solemnes siempre lleva el mismo traje. 2 Exactamente igual: Tu vestido y el mío son del mismo color. 3 Muy semejante o de igual clase: Tienes la misma forma de bablar que tu padre. [...] $\square$ Como adjetivo, precedido del artículo determinado, se usa mucho para señalar lo anteriormente mencionado: Probibida la entrada a la obra a toda persona ajena a la misma. $\square$ Como adjetivo, se usa mucho como refuerzo significativo: Yo misma se lo diré. Ellos mismos se lo han buscado. Lo oí por esta misma radio.

vox:

mis-mo, ma 1 adj.-pron. Que es la persona o la cosa que se presenta en circunstancias distintas o se relaciona con otras diferentes: es el $\sim$ hombre que vimos ayer; estos tres libros son del autor. 2 Que es muy parecido o casi igual: tiene la misma cara que su padre; soy de la misma opinión. [...] 3 Que no ha cambiado: tu bermana sigue siendo la que yo conocí; tú ya no es el $\sim$. $\square$ Se usa acompañado del artículo. 4 Que es la persona o cosa citada y no otra: tú me dijiste que me recogerías, ¿ya no te acuerdas? $\square$ Se usa acompañado de pronombres, adverbios y sustantivos: yo lo vi; ella misma hablará; el padre lo dijo. [...]

En primer lugar, registramos que estos artículos, en su totalidad, contienen una gran cantidad de datos relevantes de los cuales el aprendiz puede informarse bastante bien sobre el significado y uso de mismo en diferentes contextos. Ofrecen datos explícitos, ejemplos ilustrativos y, en el caso de SM y vox, también notas explicativas del tipo que comentamos con anterioridad. 
Como algo muy positivo se puede mencionar la cuarta acepción de SALAMANCA que indica que mismo, con este sentido, está «precedido de artículo»y «señala que la persona, animal o cosa a que se refiere no ha cambiado». También se puede mencionar la nota explicativa agregada a la cuarta acepción de vox, en la que se advierte que «se usa acompañado de pronombres, adverbios y sustantivos». Sin embargo, sorprende que los dos artículos, a pesar de aportar tres ejemplos cada uno, no hayan seleccionado ejemplos ilustrativos que incluyan «animal o cosa» $y$ «adverbios», respectivamente. Si hubieran añadido tales ejemplos serían casi perfectos.

Otro problema menor aparece en la tercera acepción de SALAMANCA, que explica que mismo puede estar «antepuesto/pospuesto a un sustantivo»y, a continuación, aporta dos ejemplos que muestran estas posiciones: «El mismo príncipe lo dijo» $\mathrm{y}$ «El principe mismo lo dijo». Todo esto constituye indudablemente una gran ayuda, pero, aun así, se puede prever que el usuario tenga dudas legítimas sobre el uso de una u otra modalidad, dado que el código «antepuesto/pospuesto» conlleva diferentes significados o matices en conexión con otros adjetivos recopilados en el mismo diccionario. Aunque el usuario no puede equivocarse con la información obtenida, las dudas pueden incitarle a emplear un tiempo excesivo en la consulta. Para evitar este inconveniente y despejar las posibles dudas, hay dos soluciones: o se añade una nota explícita informando que en este caso particular da igual que mismo esté delante o detrás del sustantivo; o se aplica el método lexicográfico de proscripción (ver Bergenholtz 2003), lo que implica que solo se selecciona y se presenta una de las dos opciones, pues tal solución es, en todo caso, suficiente para que el usuario resuelva su problema de la forma más rápida posible.

Finalmente, cabe destacar el tratamiento de mismo en la cuarta acepción de ESPASA, que informa que este adjetivo, «precedido de adverbio, refuerza su significado, añadiendo precisión»y, como ilustración, suministra el ejemplo Fue ayer $\sim$. La información que no ofrece ESPASA es que mismo, con este uso, es un adverbio como sí informan explícitamente los otros tres diccionarios en las partes que han sido eliminadas en los artículos reproducidos por tratarse de un adverbio.

¿Qué puede pensarse de esta «omisión»? Pues si volvemos a la observación de Rundell (1998) de que en los diccionarios ingleses para aprendices extranjeros «se ha sacrificado cierta delicadeza de descripción por la necesidad de obtener la máxima claridad», podemos decir que en este caso se ha sacrificado algo más que «cierta delicadeza de descripción». No obstante, desde el punto de vista del aprendiz extranjero, la información de que mismo califica como adverbio en este contexto no parece importante cuando su necesidad específica está relacionada 
con la producción de un texto en español. (Podría ser relevante si consultara el diccionario con otra intención). Incluso puede resultar más difícil para el usuario acceder a la acepción en cuestión si esta se encuentra subordinada a otra clase de palabra. Con todo, estas reflexiones no excluyen que se mencione la condición adverbial de mismo en una nota agregada a la acepción correspondiente del adjetivo mismo (ver propuesta en apartado 5) y que también se trate de forma independiente en un artículo con el adverbio mismo.

\subsection{Posible}

Como veremos, a diferencia de mismo, los artículos con posible exhiben relativamente pocos datos:

\section{ESPASA:}

po+si+ble adj. 1 Que puede ser o suceder; que se puede ejecutar: Es que llueval que lleguemos a tiempo. [...]

SMः

po+si+ble adj.inv. 1 Que puede ser o suceder: No es posible que lo que dices sea verdad. 2 Que se puede realizar o conseguir: Todavia no es posible hacer viajes en el tiempo. [...]

\section{SALAMANCA:}

posible adj. (antepuesto/pospuesto) Que puede ocurrir o ser, o que se puede hacer o conseguir: una posible solución, una solución posible. Es posible que sea así, como tú dices. El jefe me habló de un posible sustituto para el mes de junio. Es posible que vaya mañana, aunque no lo sé seguro. El acuerdo fue posible gracias a sus gestiones. [...]

vox:

po+si+ble 1 adj. Que puede ser, existir u ocurrir; que se puede realizar o lograr: es que venga hoy; si es hacerlo en menos tiempo, mejor. [...]

En estos cuatro artículos notamos cierta escasez de datos sintácticos, pues solo uno de ellos, SALAMANCA, aporta datos que tratan de su posición delante o detrás de un sustantivo. E incluso así, presta poca ayuda a sus usuarios porque 
yuxtapone dos sentidos diferentes en la misma acepción, por lo que no puede explicar cuándo se debe usar una u otra posición. A modo de ejemplo, podemos referirnos a los dos sentidos suministrados en sm y añadir que posible se antepone al sustantivo si debe expresar el primer sentido, en tanto que se pospone si debe expresar el segundo. Cabe poca duda de que esta última información es esencial para que el aprendiz pueda expresar lo que quiere decir mediante un texto sintácticamente correcto.

Otro comentario sobre el tratamiento de posible tiene que ver con su uso en combinación con oraciones subordinadas. Todos los diccionarios contienen datos sobre este uso. SM, por ejemplo, ofrece la siguiente frase: No es posible que lo que dices sea verdad. Ahora bien, como ninguno de los cuatro diccionarios aporta más datos es poco probable que todos sus usuarios se den cuenta de que el modo subjuntivo es obligatorio en este tipo de construcción. Por ello, y para aclarar las posibles dudas de los aprendices extranjeros, hace falta añadir una nota explícita que avisa que la construcción ser posible que es impersonal y siempre genera el modo subjuntivo.

\section{4 Único}

El último adjetivo que discutimos en esta sección es único:

\section{ESPASA:}

ú.ni॰co, ca adj. y s. 1 |persona, animal, cosa| Solo en su especie o grupo: Fue el $\sim$ que aprobó en toda la clase. 2 adj. Extraordinario, fuera de lo normal: un espectáculo $\sim .[\ldots]$

\section{SALAMANCA:}

único, ca adj. 1 (antepuesto/pospuesto) Que es solo en su especie: Te daré un solo y único consejo: no vayas. Soy hijo único. 2 (pospuesto) Que es extraordinario en su especie ¡ Vengan a ver este espectáculo, único en el mundo! «Don Quijote de la Mancha» es un libro único.

SM:

ú·ni.co, ca adj. 1 Extraordinario, excelente o fuera de lo común: es una mujer única y de gran generosidad. [...] adj./s. 2 Solo y sin otro de su especie: Es hijo único porque no tiene ningún hermano. Fue la única que me felicitó. 
vox:

ú.ni+co, ca 1 adj. Que es solo; que no hay otro de su especie: este coche es $\sim$ en su linea; esta chaqueta es de talla única. 2 fig. Singular, extraordinario: Juana es $\sim$.

En este caso, todos los artículos se estructuran con dos acepciones que también son las mismas que discutimos brevemente en la introducción a este texto. Sin embargo, tres de ellos no contienen ninguna indicación del importante papel que tiene la posición en relación a un sustantivo para expresar los respectivos sentidos de único. espaSA y vox ofrecen solo un ejemplo con este adjetivo como atributivo $y$, en ambos casos, está pospuesto, pero con diferentes sentidos. SM facilita dos ejemplos de este tipo, uno para cada sentido de único, pero en ambos casos está también pospuesto, lo que tampoco ayuda al aprendiz extranjero que no conozca las sutilezas de esta palabra. Una vez más, salamanca es el de los cuatro diccionarios que presta el mejor servicio a sus usuarios mediante una combinación de ejemplos y datos explícitos. Su segunda acepción es casi perfecta. En cambio, la primera manda un mensaje equívoco ya que hace falta una nota explicativa que informe al usuario de cuándo hay que usar una u otra posición. Tal nota podría explicar que único se antepone a un sustantivo cuando este está precedido de un artículo determinado o un pronombre posesivo, en tanto que se pospone cuando no está precedido de estos últimos.

Profundicemos un poco en la selección de ejemplos en sm. Para la segunda acepción, o sea, «solo y sin otro de su especie», este diccionario aporta el siguiente ejemplo con único en posición atributiva: «Es hijo único porque no tiene ningún hermano». Visto de forma aislada, se trata de un ejemplo excelente y muy didáctico porque la segunda parte subraya el significado del adjetivo en esta posición. Sin embargo, no es la posición más típica para este sentido de único. No sabemos por qué SM no ha seleccionado un ejemplo con único antepuesto a un sustantivo, pues sería sumamente relevante para sus usuarios. Si se debe a dificultades de encontrar un ejemplo adecuado en un corpus, podemos recomendar que no se obsesione tanto con los corpus y no se utilicen solo ejemplos procedentes de ellos. Desde una perspectiva didáctica, es a veces mejor redactar un ejemplo con el fin de ilustrar con toda claridad la miniregla sintáctica en cuestión.

\section{Propuestas}

Después de analizar las combinaciones sintácticas en varios diccionarios monolingües para los aprendices extranjeros de inglés, sueco y alemán, Tarp 
(2008: 242) formuló las siguientes ocho recomendaciones para los futuros diccionarios de este tipo:

- Incluir los datos sintácticos en conexión con cada sentido del lema en cuestión.

- Estructurar los datos en campos de búsqueda bien marcados.

- Siempre combinar los datos explícitos con datos implícitos mediante ejemplos $y$, si es necesario, notas explicativas.

+ Escribir en un lenguaje lo más sencillo posible.

- Evitar abreviaturas y números opacos.

- Formular minireglas en vez de códigos si la descodificación exige demasiado de los usuarios.

- Enfocar en las estructuras sintácticas superficiales en vez de sutilezas.

+ Solo usar la terminología gramatical cuando sea absolutamente necesario.

Basándonos en estas ocho recomendaciones, además de los comentarios que hemos hecho en los apartados anteriores, presentaremos a continuación unas propuestas de cómo se pueden tratar las combinaciones sintácticas en futuros diccionarios digitales para aprendices extranjeros que buscan ayuda para escribir textos en español. Las propuestas se centran únicamente en los aspectos sintácticos, por lo que no incluyen otras categorías de datos-como, por ejemplo, flexión, sinónimos, antónimos, colocaciones y expresiones fijas- datos que, por supuesto, también son imprescindibles en este tipo de diccionario.

Para permitir la comparación con los diccionarios analizados con anterioridad, partimos de la estructura semántica (incluso las definiciones) de estos diccionarios. Algunos de los ejemplos que utilizamos también se han tomado prestados de ellos, en tanto que otros han sido seleccionados mediante búsquedas en Internet y luego adaptados para que sean más didácticos. Como se verá, las propuestas comprenden siempre minireglas y ejemplos, y en algunos casos también notas explicativas e indicativas. 
(1) Propuesta de artículo con diferente:

\section{diferente ADJETIVO}

\section{DEFINICIÓN}

Que es distinto a otro; que no es igual

\section{Construcciones Sintácticas}

SUSTANTIVO + diferente

Es una sensación diferente, nunca había experimentado nada igual.

(Con este significado, se recomienda colocar diferente detrás de un sustantivo.) ser diferente

Los dos sois diferentes porque tú eres tranquila y él, nervioso.

(Se usa ser junto con diferente cuando la diferencia es de naturaleza o personalidad y se refiere a una característica estable de una cosa o persona.)

estar diferente

Con este flequillo estás diferente.

(Se usa estar junto con diferente cuando se refiere a una condición, estado o apariencia, a menudo de corta duración.)

\section{diferente a ALGO}

La vida rural es muy diferente a la que se vive en las ciudades.

(Las construcciones diferente a y diferentes de son sinónimas. Siempre se puede usar una de estas dos construcciones cuando se refiere a una cosa.)

\section{diferente a ALGUIEN}

Soy completamente diferente a mi hermano, él es alto y yo soy bajo. Tú eres diferente a ella, siempre estás alegre y ella enfadada.

(Las construcciones diferente a y diferentes de son sinónimas. Siempre se puede usar una de estas construcciones cuando se refiere a una persona.)

\section{diferente de ALGO}

La dieta de los bebés es diferente de la de las personas adultas.

(Las construcciones diferente de y diferentes a son sinónimas. Siempre se puede usar una de estas dos construcciones cuando se refiere a una cosa.) 


\section{diferente de ALGUIEN}

Soy diferente de mi mamá y de mi papá, yo soy otro. Yo no era tan diferente de ti cuando era joven.

(Las construcciones diferente de y diferentes a son sinónimas. Siempre se puede usar una de estas construcciones cuando se refiere a una persona.)

diferente (...) que + INFINITIvo

Es diferente conducir de día que hacerlo de noche.

(Se recomienda usar que en este tipo de construcción).

\section{Definición}

Varios; más de uno, cuando no son iguales

\section{Construcciones Sintácticas}

diferentes + SUSTANTIVO EN PLURAL

Hay diferentes modos de ver la misma cosa.

(Con este significado, diferentes siempre se coloca delante del sustantivo, y siempre se usa en plural.)

\section{Definición}

De manera distinta

\section{Construcciones Sintácticas}

VERBO + diferente

Su estilo ya no es el mismo, ahora pinta diferente, con más realismo.

(Con este significado, diferente siempre se coloca detrás del verbo al que califica.

Usado de esta forma, diferente funciona como adverbio y no se declina.)

(2) Propuesta de artículo con mismo:

\section{mismo ADJETIVO}

\section{i. Definición}

Que es idéntico y no una cosa o persona diferente 


\section{Construcciones Sintácticas}

mismo + ALGUIEN

Estos tres libros son del mismo autor. (Con este significado, mismo siempre se pone delante del sustantivo).

mismo + ALGO

Es el mismo coche que vimos ayer. (Con este significado, mismo siempre se pone delante del sustantivo).

\section{Definición}

Exactamente igual

\section{CONSTRUCCIONES SINTÁCTICAS}

mismo + SUSTANTIVO

Tu vestido y el mío son del mismo color. (Con este significado, mismo siempre se pone delante del sustantivo.)

\section{Definición}

Que es muy parecido o casi igual.

\section{Construcciones Sintácticas} mismo + SUSTANTIVO

Tiene la misma cara que su padre. (Con este significado, mismo siempre se pone delante del sustantivo.)

\section{Definición}

Que no ha cambiado

\section{Construcciones sintácticas ser el mismo}

Tú ya no eres el mismo que antes. Ellas son las mismas de siempre. (Siempre se usa el, la, los o las en construcciones de este tipo, también si el sujeto es yo, tú, nosotros o vosotros.)

\section{el mismo}

¿Tiene novia? - Sí, sale con la misma de hace dos años. 


\section{Definición}

Que refuerza la identidad de la persona o cosa a que se refiere.

\section{Construcciones Sintácticas}

\section{PRONOMBRE + mismo}

Yo mismo lo haré. Ellas mismas se lo han buscado. (Con este significado, mismo siempre se pone detrás del pronombre.

mismo + ALGUIEN

El mismo príncipe lo dijo. (Con este significado, mismo se pone más a menudo delante del sustantivo cuando se trata de una persona. Si se coloca detrás del sustantivo, se refuerza aún más la identidad de la persona).

mismo + ALGO

Lo oí por esta misma radio. (Con este significado, mismo siempre se pone delante del sustantivo cuando se trata de una cosa).

\section{Definición}

Señala lo que se ha mencionado con anterioridad

\section{Construcciones Sintácticas el mismo}

Prohibida la entrada a la obra a toda persona ajena a la misma. (Con este significado, mismo siempre está precedido por el, la, los o las).

\section{Definición}

Se usa detrás de un adverbio para reforzar su significado y añadir precisión.

\section{Construcciones sintácticas}

\section{ADVERBIO + mismo}

Su boda es hoy mismo. Mi mamá está allí mismo. (Con este significado y función, mismo siempre se coloca detrás del adverbio al que califica. Usado de esta forma, mismo también funciona como adverbio y no se declina). 
(3) Propuesta de artículo con posible:

posible ADJETIVo

I. DEFINICIÓN

Que puede ser o suceder

\section{Construcciones Sintácticas}

posible + SUSTANTIVo

Entre los posibles candidatos se encuentra el actual vicepresidente. (Posible siempre se coloca delante del sustantivo cuando expresa algo que puede, pero no necesariamente va a suceder, en este caso que el vicepresidente y otras personas presenten su candidatura).

\section{ser posible que + SUBJUNTIVo}

Es posible que venga una vecina a tomar café. (Siempre se usa el modo subjuntivo detrás de ser posible que. La construcción es impersonal y solo puede usarse en tercera persona singular).

\section{Definición}

Que se puede ejecutar

\section{Construcciones sintácticas \\ SUSTANTIVO + posible}

Si el dinero no alcanza sólo hay dos soluciones posibles: eliminar gastos o aumentar los ingresos mensuales. (Cuando posible está colocado detrás de un sustantivo siempre se yuxtapone a imposible, en este caso a las soluciones que son imposibles de ejecutar).

ser posible

Otro mundo es posible. ¿Son posibles los milagros?

\section{ser posible + INFINITIVo}

Es posible correr un doble maratón pero es muy doloroso. (La construcción es impersonal y solo puede usarse en tercera persona singular.) 
(4) Propuesta de artículo con único:

único ADJETIVo

I. DEFINICIÓN

Solo y sin otro de su especie

\section{Construcciones Sintácticas}

\section{único + SUSTANTIVo}

Javier es mi único amigo en España. (Con este significado, único siempre se coloca delante del sustantivo cuando está precedido por un artículo determinado, o sea, el, la, los, las, o un pronombre posesivo, o sea, mi, tu, su, nuestro, vuestro, su).

SUSTANTIVo + único

Es hijo único porque no tiene ningún hermano. Esta chaqueta es de talla única. (Con este significado, único siempre se coloca detrás del sustantivo cuando este no está precedido por un artículo determinado, o sea, el, la, los, las, o un pronombre posesivo, o sea, mi, tu, su, nuestro, vuestro, su).

ser el único

Marta es la única que puede resolver este problema con éxito. Vosotros sois los únicos que no me han traicionado. (Siempre se usa el, la, los o las en construcciones de este tipo, también si el sujeto es yo, tú, nosotros o vosotros.)

\section{Definición}

Extraordinario, excelente o fuera de lo común

\section{Construcciones Sintácticas \\ SUSTANTIVo + único}

Eres una amiga única y fantástica, gracias por todos los momentos vividos a tu lado. (Con este significado, único siempre se coloca detrás del sustantivo.)

\section{ser único}

Sois únicos, jamás me había imaginado tener amigos tan solidarios como vosotros. 


\section{Conclusiones}

Cabe destacar que los artículos propuestos en el apartado anterior están pensados para un diccionario concebido desde cero para el medio digital y descrito en más detalles por Nomdedeu \& Tarp (2018). Este punto de partida garantiza una capacidad de almacenamiento casi ilimitada y permite, al mismo tiempo, que se apliquen varias técnicas para evitar una presentación excesiva de datos que confunde al usuario y obstaculiza la consulta; ver Gouws \& Tarp (2017). Como consecuencia, los datos lexicográficos que se ven en los artículos propuestos son los que se almacenarán en la base de datos que sostiene el diccionario, pero no necesariamente los que se presentarán de inmediato al usuario. Esta flexibilidad tiene especial relevancia debido a la próxima introducción de una nueva generación de asistentes de escritura que incorporan diccionarios «inteligentes» capaces de «observar» a sus usuarios y ofrecerles soluciones que se adaptan a cada contexto concreto; ver Tarp et al. (2017).

Además, nuestras propuestas presuponen que se añade una dimensión bilingüe para prestar un mejor servicio a los usuarios. Esto implica, por un lado, que se incluirá un puente L1-L2 de acceso a los artículos visualizados, y, por otro lado, que se facilitarán equivalentes y traducciones de las definiciones, minireglas, ejemplos y notas explicativas, todo esto en la L1 del usuario y combinado con notas pragmáticas-culturales cuando hay diferencias relevantes entre L1 y L2.

La idea es que esta opción bilingüe puede activarse y desactivarse según las preferencias y necesidades del usuario individual en cada caso. De esta manera, se toma en consideración que el grupo destinatario está compuesto por un abanico de aprendices extranjeros que tienen diferentes lenguas maternas, diferentes niveles de dominio del español y, por ende, diferentes tipos de necesidades en lo que se refiere a los datos lexicográficos, su acceso y su lectura.

Este concepto encaja en las reflexiones más recientes dentro de la lexicografía pedagógica donde la tendencia mayoritaria -después de unas décadas centradas en el diccionario monolingüe como el mejor tipo de diccionario para los aprendices extranjeros (Hernández 1990, Scerba 1995)- hoy en día favorece el tipo de diccionario que conecta con la lengua materna del usuario; ver Ruhstaller (2004), Tarp (2006), Augustyn (2013) y Adamska-Salaciak \& Kernermann (2016).

Por nuestra propia experiencia como profesores no nativos de español, estamos plenamente de acuerdo con esta visión. 


\section{Referencias bibliográficas}

\subsection{Diccionarios consultados}

BIENVEnidos = Lorenzo Martín, I. (2011). Bienvenidos. El primer diccionario de español. Barcelona: Octaedro.

DAele $=$ Battaner Arias, P. y J. DeCesaris. En línea. Diccionario de Aprendizaje de Español como Lengua Extranjera. Barcelona: Institut Universitari de Lingüística Aplicada, Universitat Pompeu Fabra. [httpः//www.iula.upf.edu/rec/ daele/. último acceso 15-10-2018].

ESPASA = Villar, C. (ed.) (2002). Diccionario de la lengua española para estudiantes de español. Madrid: Espasa-Calpe.

salamanca = Gutiérrez Cuadrado, J. (ed.) (1996). Diccionario Salamanca de la lengua española. Madrid: Santillana / Universidad de Salamanca. [http:// fenix.cnice.mec.es/diccionario/. último acceso 15-10-2018].

sm = Maldonado González, C. (ed.) (2002). Diccionario de español para extranjeros. Madrid: Editorial SM.

vox = Alvar Ezquerra, M. (ed.) (2000). Diccionario para la enseñanza de la lengua española. Español para extranjeros. Alcalá de Henares: VOX, Universidad de Alcalá de Henares / Spes Editorial. [http://www.diccionarios.com/ último acceso 15-10-2018].

\subsection{Otra literatura}

Adamska-Salaciak, A. y I. Kernermann (2016). «Towards better dictionaries for learners». International Journal of Lexicography, 29 (4):271-278.

Al-Kasımi, A. M. (1977). Linguistics and Bilingual Dictionaries. Leiden: E.J. Brill. Augustyn, P. (2013). «No Dictionaries in the Classroom: Translation Equivalents and Vocabulary Acquisition». International Journal of Lexicography, 26 (3): 362-385.

Bergenholtz, H. (2003). «User-oriented Understanding of Descriptive, Proscriptive and Prescriptive Lexicography». Lexikos, 13: 65-80.

Cos Ruiz, F+ J. de (2004). «La información sintáctica en las gramáticas y los diccionarios de ELE: propuesta de explicación del complemento predicativo». En: M. A. Castillo Carballo, O. Cruz Moya, J. M. García Platero y J. P. Mora Gutiérrez (eds.). Las gramáticas y los diccionarios en la enseñanza del español como segunda lengua: deseo y realidad. Sevilla: Universidad de Sevilla: 280-287. 
Cowie, A. P. (1987). «Syntax, the Dictionary and the Learner's Communicative Needs». En: A. P. Cowie (ed.). The dictionary and the language learner. Tübingen: Niemeyer: 183-192.

Cowie, A. P. (1989). «Information on Syntactic Construction in the General Monolingual Dictionary». En: F. J. Hausmann, O. Reichmann, H. E. Wiegand y L. Zgusta (eds.). Wörterbücher, Dictionaries, Dictionnaires. An International Encyclopedia of Lexicography, First Volume. Berlin, New York: Walter de Gruyter: 588-592.

DAM, L. (2008). «La posición del adjetivo atributivo español. Un enfoque instruccionalista sobre la noción de focalización». Español actual: Revista de español vivo, 89: 7-38.

DAM, L. y H. DAM JENSEN (2018). Spansk universitetsgrammatik: former og kontekst. Aarhus: Aarhus Universitetsforlag.

DeKeyser, R. M. (2005). «What Makes Learning Second-Language Grammar Difficult? A Review of Issues». Language learning, A Journal of reserach in Language Studies, 55 (1): 1-25.

Delbecque, N. (1990). «Word order as a reflection of alternate conceptual construals in French and Spanish. Similarities and divergencies in adjective position». Cognitive Linguistics, 1(4): 349-416.

Demonte, V. (1999). «El adjetivoः clases y usos. La posición del adjetivo en el sintagma nominal». En: I. Bosque y V. Demonte (eds.). Gramática descriptiva de la lengua española. Madrid: Editorial Espasa: 129-215.

Fuertes-Olivera, P. A. y S. Tarp (2014). Theory and practice of specialised online dictionaries: Lexicography versus terminography. Berlin, Boston: De Gruyter.

Garrudo Carabias, F. (2004). «El diccionario, arma de doble filo: la información gramatical». En: M. A. Castillo Carballo, O. Cruz Moya, J. M. García Platero y J. P. Mora Gutiérrez (eds.). Las gramáticas y los diccionarios en la enseñanza del español como segunda lengua: deseo y realidad. Sevilla: Universidad de Sevilla: 41-52.

Gómez Torrego, L. (2011). Gramática didáctica del español. Madrid: Ediciones SM.

Gouws, R. H. y S. Tarp (2017). «Information overload and data overload in lexicography». International Journal of Lexicography, 30 (4): 389-415.

Herbst, T. (1989). «Grammar in Dictionaries». En: M. L. Tickoo (ed.). Learner's Dictionaries: the State of the Art. Singapore: SEAMO Regional Language Centre: 94-111. 
Hernández Hernández, H. (1990). «Hacia un modelo de diccionario monolingüe del español para usuarios extranjeros». En: R. Fente Gómez y J. A. de Molina Redondo (eds.) (1990). El Español como Lengua Extranjera: Aspectos Generales (Actas del Primer Congreso Nacional de ASELE, 1989). Granada: Publicaciones de la Universidad: 159-166.

Jackson, H. (1985). «Grammar in the Dictionary». En: Robert Ilson (ed.). Dictionaries, Lexicography and Language Learning. Oxford: Pergamon Press, British Council, 53-59.

Jensen, K. (2008). Ny spansk grammatik. Copenhague: Akademisk forlag. Mogensen, J. (2001). Spansk grammatik. Taastrup: Forlaget don Quijote.

Nomdedeu Rull, A. y S. Tarp (2018). «Hacia un modelo de diccionario en línea para aprendices de español como LE/L2». Journal of Spanish Language Teaching, 5 (1): 50-65. [DOI: 10.1080/23247797.2018.1459279].

Real Academia Española (1973). Esbozo de una nueva gramática de la lengua española. Madrid: Espasa Calpe.

Real Academia Española (2009). Nueva gramática de la lengua española. Morfología Sintaxis I. Madrid: Espasa Libros.

Ruhstaller, S. (2004)* «Consideraciones sobre los diccionarios monolingüe y bilingüe». En: M. A. Castillo Carballo, O. Cruz Moya, J. M. García Platero y J. P. Mora Gutiérrez (eds.). Las gramáticas y los diccionarios en la enseñanza del español como segunda lengua: Deseo y realidad. Sevilla: Universidad de Sevilla: 86-93.

Rundell, M. (1998). «Recent Trends in English Pedagogical Lexicography». International Journal of Lexicography, 11 (4): 315-342.

Santamaría Pérez, I. (2004), «La información gramatical en los diccionarios monolingües de aprendizaje: reflexiones a partir del verbo». Estudios de lingüistica: 559-580.

Scerba, L. V. (1995). «Towards a General Theory of Lexicography». International Journal of Lexicography, 8 (4): 315-350.

Seco, M. (1987). «El 'contorno' en la definición». En: M. Seco (ed.). Estudios de lexicografía española. Madrid: Paraninfo: 35-45.

Sweet, H. (1899). The Practical Study of Languages: A Guide for Teachers and Learners. London: Oxford University Press.

TARp, S. (2006). Lexicografía de aprendizaje. Cadernos de tradução, XVIII: 295 317.

TARP, S. (2008). Lexicography in the borderland between knowledge and non-knowledge. General lexicographical theory with particular focus on learner's lexicography. Tübingen: Niemeyer. 
TARP, S. (2011). «Lexicographical and other e-tools for consultation purposes: Towards the individualization of needs satisfaction». Enः P. A. Fuertes-OLivera y H. Bergenholtz (eds.). e-Lexicography: The Internet, Digital Initiatives and Lexicography. London, New York: Continuum: 54-70.

TARp, S. (2018). «El desafío de los datos sintácticos en los diccionarios para aprendices extranjeros del español». Revista de Filología de la Universidad de La Laguna, 36:367-391.

Tarp, S., K. Fisker y P. Sepstrup (2017). «L2 write assistants and context-aware dictionaries: New challenges to lexicography». Lexikos, 27: 494521.

Tono, Y. (1986). «A scientific approach toward lexicography»+ LEO, Journal of the Linguistic, Literary and Educational Organization, 15: 37-53.

\section{ANEXO}

Lista de las 31 oraciones en danés traducidas al español. Los adjetivos centrales quedan indicados en paréntesis después de cada oración danesa.

1. Denne prototype blev udviklet af virksomheden selv. (propio) 'Este prototipo fue desarrollado por la propia empresa'.

2. De har ikke egen bil. (propio) 'No tienen coche propio.'

3. For de fleste unge familier er det en utopi at få egen bolig. (propio) 'Para la mayoría de las familias jóvenes, es una utopía acceder a la vivienda propia.

4. Valg af hobby er særligt for hvert enkelt menneske. (propio)'La selección de un hobby es propia de cada persona.'

5. Den stakkels dreng kunne ikke finde sin mor. (pobre) 'El pobre niño no pudo encontrar a su madre.'

6. De så mange fattige børn i Etiopien. (pobre) 'Vieron a muchos niños pobres en Etiopía'

7. De fandt mange antikke spejle på markedet. (antiguo)'Encontraron muchos espejos antiguos en el mercado.'

8. De skiftede de gamle tagrender ud. (antiguo) 'Cambiaron los antiguos canalones.' 
9. Det halve af byen deltog i byfesten. (medio) 'Media ciudad participó en la fiesta.'

10. Hun købte en halv meter stof. (medio) Compró medio metro de tela.

11. En halv million unge demonstrerede på Rådhuspladsen. (medio) Medio millón de jóvenes se manifestaron en la Plaza del Ayuntamiento.

12. Den gennemsnitlige pris er 250 Euros. (medio) El precio medio es 250 euros.

13. Til en vis grad er det nødvendigt at kunne de mest almindelige regnearter. (cierto) Hasta cierto grado, es necesario poder realizar las operaciones aritméticas más simples.

14. Produkterne indeholder en vis mængde vand. (cierto) 'Los productos contienen cierta cantidad de agua'.

15. Filmen bygger på sande begivenheder (cierto)'La película se basa en eventos ciertos.'

16. Det er den sidste hvide tiger i området. (último) 'Es el último tigre blanco en el área?'

17. De købte billetterne til selve forestillingen. (mismo) Compraron las entradas en el (mismo) espectáculo (mismo).'

18. Jeg har købt de samme billetter. (mismo) He comprado las mismas entradas.

19. Det er de studerende selv der skal melde sig til eksamen. (mismo) 'Son los mismos estudiantes los que deben matricularse al examen.'

20. Der er adskillige personer der ikke kan lide romanen. (varios) 'Hay varias personas que no están contentas con la novela'

21. Nogle af disse vandplanter har forskelligartede anvendelser. (varios)'Algunas de estas plantas acuáticas tienen usos varios.'

22. Politiet har anholdt den formodede gerningsmand (presunto) 'La policia ha detenido al presunto autor del delito'.

23. Det er ren propaganda. (puro) 'Es pura propaganda'. 
24. Armbåndet er af ren guld. (puro) 'La pulsera es de oro puro.'

25. På restauranten kan gæsterne vælge mellem forskellige retter. (diferente) 'En el restaurante, los visitantes pueden elegir entre (diferentes) platos (diferentes).'

26. Gruppen er sammensat af ansatte med forskellige egenskaber (diferentes)'El grupo está compuesto de empleados con (diferentes) cualidades (diferentes).'

27. Javier er blandt de mulige vindere. (posible) 'Javier se encuentra entre los posibles ganadores.'

28. Der er kun to mulige løsninger: at spare eller at arbejde mere. (posible) 'Solamente hay dos soluciones posibles: ahorrar o trabajar más.'

29. Javier er en enestående ven. (único) 'Javier es un amigo único.'

30. Du er den eneste der kan gøre det. (único) 'Eres la única que puede hacerlo'

31. Hun er min eneste søster. (único) 'Es mi única hermana.'

\section{Agradecimiento}

Agradecemos al Ministerio de Economía y Competitividad de España (Proyecto con Ref. FFI2014-52462-P) la financiación aportada para la realización de este trabajo. 